Combes, B., \&. Anderson, K. (2006). Supporting first year e-learners in courses for the information profession. In C. Khoo, D. Singh \& A.S. Chaudhry (Eds.), Proceedings of the Asia-Pacific Conference on Library \& Information Education \& Practice 2006 (A-LIEP 2006), Singapore, 3-6 April 2006 (pp. 587597). Singapore: School of Communication \& Information, Nanyang Technological University.

\title{
SUPPORTING FIRST YEAR E-LEARNERS IN COURSES FOR THE INFORMATION PROFESSIONS
}

\author{
BARBARA COMBES \& KAREN ANDERSON \\ School of Computer and Information Science, Edith Cowan University \\ 2 Bradford Street, Mount Lawley, WA, Australia 6052. \\ Email: b.combes@ecu.edu.au, keanders@optusnet.com.au
}

\begin{abstract}
A considerable amount of research has been done into students' first year experiences at university: their transition from school to university studies and their social needs and experiences. The work described in the literature has concentrated on students who attend school on campus. If on-campus students are experiencing problems with feeling isolated, a lack of identity and feeling part of a community, then how do distance students deal with these same issues? A research project conducted at Edith Cowan University in 2004-2005 sought to discover the issues affecting first year students and the problems they experienced when beginning studies in online professional education programs for librarians, library technicians, teacher librarians, archivists and records managers. Many of these students in the School of Computer and Information Science (SCIS) study by distance education and are wholly dependent on elearning. There are others who attend on campus but undertake a significant proportion of their studies through elearning. Communication and IT skills and preparedness must be added to the list of major first year experience issues for this group. Two separate studies were initiated to find out how the online environment differs from the on-campus experience, how students feel about studying online and what needs to be included to facilitate a more supportive experience at university. The results of these two studies - First experiences of online university study and Using discussion forums to create an online learning community - are reported here.
\end{abstract}

\section{Introduction}

Technology has become an integral part of the everyday information landscape. It is global in nature and increasingly user-friendly and cost efficient. It allows users to be mobile, connected and accessible. Users also have access to a wide range of information resources at any time and from any location. In such an information environment "new technologies are changing modes of learning, collaboration, and expression" (Duderstadt et al. (2005). For universities steeped in traditional delivery modes, this new information landscape has led to changes in infrastructure and course delivery and questions about traditional pedagogy. Many younger students working in multi-format learning environments in secondary schools expect similar opportunities to use technology in their learning at university. However, since universities cater for diverse populations, the needs of older students returning to study must also be considered. Catering for these diverse student groups and introducing change (often rapid change) to delivery modes, pedagogy and support infrastructure present a challenge for universities and academics to "ensure that the canonical activities of universities - research, teaching, and engagement - remain rich, relevant, and accessible" (Duderstadt et al. (2005).

In many cases, universities have embraced technology at an administrative level, while teaching methodologies remain largely the same: the traditional lecture, with perhaps a PowerPoint slide show instead of a series overheads, text handouts or notes on the white board. In many universities the technology employed for learning consists of learning management systems (LMS) such as WebCT, BlackBoard or the Edith Cowan University (ECU), School of Computer and Information Science's (SCIS) home-grown system, eCourse. These systems are used to deliver course materials to students many of whom now study wholly online. Five years ago it was predicted that developments in technology would "revolutionize learning, empower students and faculty, democratize knowledge production, and transform society" (Werry, 2002). However, a recent report from the US tertiary sector, Thwarted Innovation: What happened to elearning and why? (Zemsky, \& Massy, 2004), which examines elearning initiatives across sixteen universities, found that students do not view or use technology and electronic resources as learning tools. While students want to be connected to each other, they view elearning as a convenience at best and a distraction at its worst. Their primary use for the Internet is for communication and entertainment. While the universities in the study were using learning management systems, these were being used for administrative purposes and as a delivery platform, rather than a facility to integrate technology and different teaching-learning experiences into courses. As for the assumption that technology would force a change in the way academics teach, the authors concluded: "not by a long shot" (Zemsky, \& Massy, 2004). Results from this report may indicate why many of the 
early elearning or virtual universities and e-education companies have gone out of business (Werry, 2002), a disturbing trend that needs to be investigated further by educational institutions providing online courses. Have these ventures been unsuccessful due to the mode of delivery (ICTs), other factors that affect student learning in the online environment or is it the skill levels and attitudes of students?

This paper reports on two separate studies that emerged from the SCIS LMS Work Group, a committee comprising academics, technical and general staff; an instructional designer and SCIS students. The main purpose of this group is to provide feedback, trouble-shoot current issues and to facilitate the ongoing development of an overarching philosophy and direction for online learning in the School. The main aim of this approach is to cultivate a whole school teaching-learning culture and to build a learning community within SCIS. While the Group has succeeded in creating an online community at SCIS that is heavily utilised by on-campus and online students (Anderson et al. 2005), anecdotal feedback and attrition rates for students studying online indicate that there are some issues with this delivery mode. Two separate studies were initiated to find out how the online environment differs from the oncampus experience, how students feel about studying online and what needs to be included to facilitate a more supportive experience at university. The results of these two studies - First experiences of online university study and Using discussion forums to create an online learning community - are reported here.

\section{First Experiences of Online University Study}

The purpose of this research was to inform the School of Computer and Information Science (SCIS) about students' experiences with online learning. Since all students are required to use the online delivery mode when studying SCIS units, the main purpose of this study was to find out how students perceive and cope with this mode of delivery. The study focussed on first time users of technology and students studying from a distance. A pilot study was conducted with Library and Information Science (LIS) students in 2004 using an anonymous web survey. The survey instrument was refined for the 2005 study to include questions about the discussion forums and the online orientation activities introduced in some units as a result of the feedback received in the pilot study.

The survey focussed on students' initial experiences when using technology for study, their attitudes to the learning experience and expectations. Another aspect of this research was to determine if there is a connection between common issues identified in the literature about first year experiences (FYE) at university and students who study online. The FYE research only deals with students studying on campus. Do online students have the same issues or does the use of the technology introduce other factors? FYE research has identified isolation and lack of identity, being unprepared for university academically, dissatisfaction and a lack of motivation to study, as major impediments to success at university in the first year (McInnes, 2000). Other major issues include anxiety, poor adjustment to university culture and a lack of continuity of curriculum (Latham \& Green, 1997). Research also reports that students prefer face-to-face instruction, interactive lectures and group-based activities (Sander et al, 2000), although they welcome online materials as an enhancement to the on-campus learning environment (Oliver \& Omari, 2001).

The literature about students' perceptions of online learning reports that students prefer face-toface communication (Salmon, 2002) and that this preference is strongly related to students establishing a sense of identity and feeling connected and integrated with the university (McInnes, 2000). For students working entirely in an online learning environment, where communication is text based and there are no visual cues, establishing a sense of identity and community is a difficult task that requires time. $\mathrm{Tu}$ and Corry (2001) suggest that there is a threshold of familiarity when studying with computers. Students need time to establish an online self and an online social presence. Salmon also tells us that "experienced participants introduced to an unfamiliar online learning platform will still go through a familiarisation, access and motivation stage" (Salmon, 2002, p. 12). The Committee for the Advancement of University Teaching ( CAUT) Review (McInness et al, 1995) into FYE anticipated that the proportion of students who manage to attain a sense of identity will fall with increases in flexible delivery, the number of online courses and the many students who choose not to attend on-campus lectures due to work commitments. A review of this research conducted in 2000 substantiated the findings and predictions of the earlier report (McInness et al, 2000). Oliver has also suggested that students of a mature age entering university for the first time, have poor technology skills (Oliver, 2003). In the case of students who study only online, this may affect their capacity to cope with the online environment. A small case study by Hara and Kling (1999) examined student reactions to studying a course wholly online. They found that student anxiety and frustration had a major effect on student learning. In this 
study a lack of prompt feedback, ambiguous instructions contained in the learning materials and technical problems markedly diminished student satisfaction and inhibited educational opportunities.

Research into the importance of student readiness for effective online learning programs does not consider the emotional response of the student to the total experience of studying online. Current research tends to discuss, in general terms, the importance of the learning 'space', the establishment of student identity and student readiness in terms of technical skills acquisition (Tu \& Corry, 2001; Salmon, 2002; Oliver, 2001). This study looks at students' emotional response and reactions to studying online and targets a specific group of students, the Library and Information Science (LIS) students at Edith Cowan University.

\section{Method}

A pilot study conducted in 2004, using an anonymous web survey received responses from forty-four participants. Students studying LIS units were invited to participate in the survey via closed discussion forums (asynchronous bulletin boards) on eCourse: the Lib Tech (Library Technology) Hub, the TL (Teacher Librarian) Hub and the Archives and Records Hub. These general discussion forums were created to provide an open discussion space for online and on-campus students in an attempt to develop a sense of community for all students. The survey was originally designed to target only LIS students. However, unknown to the researcher, the forums were opened up to LIS and other students, including those students completing single computer science units which are components of the undergraduate degree in Library Technology and the double degree in Communication and Information Technology and Library Technology. Although the sample population was contaminated in the pilot study, some interesting results emerged that were used to inform the 2005 study.

\section{The Pilot Study}

While FYE research has identified isolation and lack of identity as major impediments to success at university in the first year (McInnes, 2000), the literature does not consider lack of confidence or frustration as issues for first time students. The findings from the pilot study suggest that lack of confidence, frustration, feelings of isolation and anxiety are closely related and significant issues for online students. The study also suggests that the lecturer is a central figure in the online learning environment. The presence of a pro-active lecturer who gives prompt feedback, has and maintains early and consistent contact with students, appears to counter-balance the students' need and preference for face-to-face instruction as identified in the FYE literature. Students in the pilot study who felt comfortable using the Internet for online study, also felt successful and confident, were confident using the discussion forums and appeared to enjoy the online experience. While a number of students were still experiencing technical difficulties, the frustrations and increased anxiety experienced by students and described in the literature (Hara and Kling, 1999), appeared to be associated more with lack of confidence and feelings of isolation in this survey group than technical readiness. These results may be due to the fact that the eCourse system is extremely robust and students experienced very little down time during the semester. The age of students has also been identified in the literature (Oliver, 2003) as a suggested factor that influences success at university. It has been suggested that mature age students entering university for the first time have poor technology skills.

\section{FYE Project Results}

The 2005 survey invited 200 LIS students to participate in the study via their personal student email, thus eliminating issues about the target population. The survey used a four-point Likert scale to encourage students to make a decision about their feelings. Forty-six students responded to the survey, however, 2 responses were deleted as anomalies. These responses appeared to have been generated by the same person (they had the same identifying code and only the strongly disagree response was generated throughout the survey. Since, the survey contained a number of negative questions/statements, these 2 responses were eliminated from the survey. Therefore, forty-four students $(22 \%$ of the target population), mostly female (93\%) responded to the survey. Demographic information about the survey group is summarised in Table 1 below. 
Table1: Demographic data

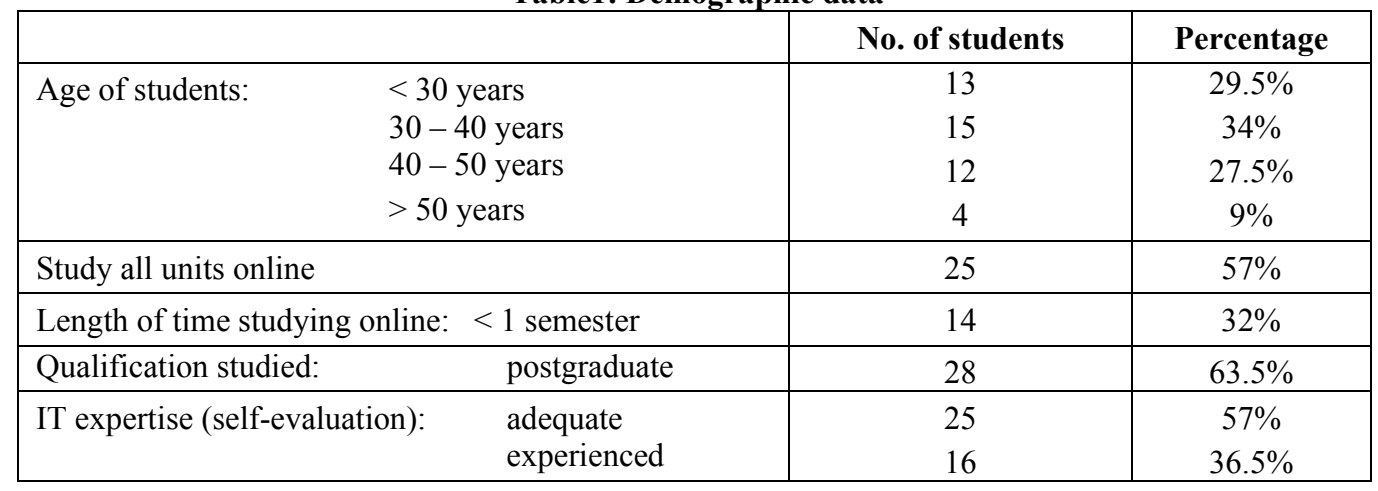

Age

The demographic data indicates that the LIS student group is generally older, which suggests they are either embarking on a career change, updating existing qualifications or coming back to study after a break, as in the case of married women with families. This result was similar to the pilot study. The age of the respondents was not a significant factor in student IT skill levels, how students felt about using the Internet for study, feeling isolated, lack of confidence or motivation. Rather, the length of time studying online affected students' attitudes and engagement. More than half of the cohort were studying wholly online and fourteen students had been studying for less than one semester. Students who had been studying online for longer than a semester were more confident $(r=0.5462, p<0.0005)$ and had fewer reservations about using the discussion forums $(r=-0.6402, p<0.0005)$.

\section{IT Skill Levels}

The majority of students reported they had adequate IT skills for their needs or considered themselves to be experienced users. This result may indicate that technical readiness and computer/ICT literacy are becoming less significant as more students already have these skills. However, the LIS group contains many students who are already working in libraries and who require a certain level of computer literacy as part of their skills set. It is difficult to draw any definite inferences using this group of students. A wider study containing a range of students from across faculties would be required to find out if students' computer and ICT literacy levels are actually rising. However, these results were similar to those obtained in the pilot study and tend to debunk the suggestion that older students entering university do not have IT skills or that age may affect how successfully they deal with online learning (Oliver, 2003).

\section{Technical Readiness}

Similar to the pilot study, almost a third of the cohort reported ongoing technical difficulties with their equipment $(29.5 \%)$, their Internet service provider $(23 \%)$ and problems accessing the necessary equipment to study online (27.5\%). Although the students' perceived IT skill levels were high, user skill levels were directly related to technical difficulties $(\mathrm{r}=0.4267, \mathrm{p}<0.005 ; \mathrm{r}=0.7494, \mathrm{p}<0.0005$; and $\mathrm{r}$ $=0.5420, p<0.0005)$. Students who felt they were inexperienced users also experienced an increased lack of confidence $(r=0.693, p<0.0005)$. These results raise interesting questions about the provision of technological support for online students and assumptions made by institutions about the availability of the Internet for students studying remotely. In the case of the LIS cohort at ECU, students may be studying in remote outback areas in far north Queensland and central Australia or overseas. In many instances, the robustness and availability of the Internet is an issue for students. These factors are totally outside the students' control and must introduce a level of frustration and anxiety into the online learning experience.

\section{Isolation and Motivation}

In both the pilot and the 2005 study, the mode of delivery was a significant factor in how student's felt about their study, their level of confidence and motivation. The 2005 study produced a negative correlation $(\mathrm{r}=-0.5680, \mathrm{p}<0.0005)$ indicating that the mode of study is significant for both online and mixed mode students. It seems that the online experience raises issues for all students, not just those studying wholly online. Both on-campus and online students felt a degree of isolation when studying 
units online. Similar to the pilot study, students who feel isolated also lack confidence using the Internet for their study $(\mathrm{r}=0.6933, \mathrm{p}<0.0005)$ and cited a lack of motivation $(\mathrm{r}=0.4008, \mathrm{p}<0.005)$ as an issue. Students who feel isolated also want earlier and more consistent contact with the lecturer $(\mathrm{r}=$ $0.4237, \mathrm{p}<0.005)$.

The importance of the online facilitator/lecturer/tutor is a significant factor in how students react to and cope with the online learning environment (Salmon, 2001; Doubler et al, 2003). In this study thirty-six students (81.5\% agreed, $29.5 \%$ strongly) cited earlier contact with the lecturer as a way of improving their experiences online. Students who felt isolated also wanted more information about studying online. They wanted more information about the university systems, the LMS being used by the school, requirements for the unit and how to study online. Even though the respondents in this survey were predominantly postgraduate students $(63.5 \%)$ who already have an undergraduate qualification and previous experience with university culture and expectations, they also wanted more information about expectations and the skills necessary to be successful at university $(r=0.5160, p<0.0005)$. Since a large proportion of students had already studied at university previously, it would appear that the need for more information is a factor related to the mode of study rather than the study itself or university expectations and culture. For these students the sense of physical isolation and lack of belonging to a teaching-learning community is a major issue.

Research into FYE identify isolation and lack of identity as key factors in students establishing a sense of identity and feeling connected and integrated with the university (McInnes, 2000). While aware of the first element of isolation when they enrol, students may not have been prepared for the loneliness of studying at a distance, where there is no immediate access to lecturers and peers to answer questions. The results also suggest that the isolating elements characteristic of being part of a large university may also be exacerbated by the online delivery mode. Students felt that more information and earlier contact with the lecturer were the keys to overcoming feelings of isolation.

Lack of motivation is also a factor cited in the literature as a major impediment to success at university in the first year (McInnes, 2000). In this study, students felt that a lack of motivation could be overcome by earlier contact with the lecturer. Early and consistent contact with students by the lecturer may help online students overcome lack of motivation, but this may not always be a solution since other factors may be involved. Students felt that earlier and more consistent contact with the lecturer would alleviate their confidence issues $(r=0.4378, \mathrm{p}<0.005)$ when using the Internet for study. These results support FYE research that places the lecturer as a key player in determining student satisfaction with the university experience (Salmon, 2001; Doubler et al, 2003).

\section{Confidence and Anxiety}

A major result from the survey concerns lack of confidence as an issue for online students, with $47.5 \%$ citing lack of confidence when using the Internet for their study. When asked whether lack of confidence was an aspect of online study that applied to them, 59\% of students agreed. Students who lacked confidence also felt isolated $(\mathrm{r}=0.4008, \mathrm{p}<0.005)$. These feelings applied to students studying mixed mode (on campus and online) and to students studying entirely online. Students who lacked confidence wanted more practical assistance when logging on to the University systems and eCourse $(\mathrm{r}=0.6044$, $\mathrm{p}<0.0005)$, more information about requirements for the units $(\mathrm{r}=0.4129, \mathrm{p}<\mathrm{x} 0.005)$, more information about expectations and the skills necessary to be successful at university $(r=5160, p<0.0005)$, more information about how to study online $(\mathrm{r}=0.4265, \mathrm{p}<0.005)$ and earlier contact with the lecturer/tutor $(\mathrm{r}=0.4378, \mathrm{p}<0.005)$. Students who were confident also had fewer reservations about using the discussion forums $(\mathrm{r}=-0.6263, \mathrm{p}<0.0005)$. Once again, students who lacked confidence felt that earlier and more consistent contact with the lecturer would alleviate their confidence issues $(r=0.4378$, $\mathrm{p}<0.005)$.

Anxiety is also a feature of the online study environment with $51 \%$ of students $(18.5 \%$ strongly agreeing) experiencing anxiety when using the Internet for study. Students who were anxious felt that more information about the university and SCIS systems would help to relieve this aspect of studying online $(\mathrm{r}=0.9116, \mathrm{p}<0.00005$ and $\mathrm{r}=0.8029, \mathrm{p}<0.00005)$. Students who did not experience anxiety also had fewer reservations about using the discussion forums $(\mathrm{r}=-0.8588, \mathrm{p}<0.0005)$. Interestingly, anxiety also correlated with the age of the student $(\mathrm{r}=0.4012, \mathrm{p}<0.005)$, but not necessarily with the older students $(40+)$.

Confidence, self-efficacy and anxiety are important factors in student health and well-being and affect how students cope in stressful situations such as feeling isolated and being able to manage the adjustments required to be successful at university. The fact that so many students did not feel confident and cited anxiety as an issue when using the online delivery mode for study, indicates that the mode of 
delivery may well be an important factor that influences success at university. While discussion forums, where students can talk online with their peers and the lecturer are one way of building a learning community, the results of this study indicate that confidence and anxiety may impede students' ability to engage in the discussion forums. For online students to feel confident and part of a learning community, lecturers will need to establish contact early, provide information on how to use the forums and endeavour to make the transition to online study and university as anxiety-free as possible.

\section{Student Comments}

For students working in an online environment, isolation, lack of confidence and anxiety are real issues that are an integral part of their experience at university. The research suggests that students go through an initial phase of uncertainty each time they begin a new unit (Salmon, 2002; Tu \& Corry, 2001). Students who responded to the survey were also asked to add any other commentary about their experiences. Twenty-seven students or $61 \%$ of the survey group included additional commentary This high response rate may be due to a number of factors:

- $\quad$ reflects the type of student in the LIS group;

- indicates that online learning is a topic that students feel strongly about; and/or

- deals with new experiences and students feel a need to provide feedback.

Contact and communication with the lecturer were frequently quoted in the student commentary. Lack of contact also increases anxiety, lack of confidence and feelings of isolation as evidenced in the data. Online students felt they were missing out on vital information that was available to on campus students. Students wanted more help to resolve these issues.

"I am in my third semester now and sympathise with new "onliners" as they show the same signs of frustration that I had when I started. I think the worst thing is, if you are having a hard time getting it all together \& it's your first semester - and all you have is a you a pc and an online address - it is difficult, lonely and frustrating to get organised especially re: logins etc. I would like to say that the support I have received has at times helped me to keep going - from both teacher and fellow students.” (Student \#36)

"It is nowhere near as enjoyable as attending lectures and tutorials. You miss all the extra information that you would gain from body language, life experience (stories, examples) from the lecturer." (Student \#14)

Technical support and issues with the technology affected nearly a third of the students and appears to have been a major issue that has soured the online learning experience. In many cases the problems experienced by students is beyond the control of the lecturer or the university, but courteous and helpful advice from IT support personnel will make student experiences more positive.

"When I first started ADSL was slowly being introduced in my area. I found dial-up to be totally inadequate for online study, but have had no problem since getting a much faster, unlimited broadband connection." (Student \# 11)

"This semester is the first time I have had to use chatrooms for tutorial workshops. although it is good to 'speak' directly to my tutor and fellow students, there are many technical problems, such as the internet connection failing. when you log-in again you can't see what has been 'said' before so you loose everything ad/or miss out. I think the discussion group postings are better because you can see what everyone has said anytime." (Student \#24)

Several students commented on the amount of reading required for university study, particularly when using a screen and wanted readers in print format. Motivation and time management were also issues for online students, especially those who were working or juggling family responsibilities.

"Motivation and time management skills can not be emphasised enough. Even though I can do all my units on campus I find it very difficult to study and run a family as they do not seem to think I am doing 'real' stuff and can drop it anytime. (Student \#23)

"Mentally unprepared for online study, not knowing what that entails." (Student \# 31)

"It is very hard to find the motivation to sit down and do work at home. I feel I need structured times to do things, not write up my own timetable and follow it as this rarely happens. Plus in my house I must compete with an older brother (who owns the computer) for computer time and my parents don't really see studying at home as actual studying. In relation to 
assignments, you don't get the same support as you would in class where all students can ask questions about it and allow you to get a clearer understanding of what is needed." (Student \#44)

For students who dislike online as a mode of delivery, the response was passionate.

"The assumption that an online subject is an equal substitute for wanting to study that subject on campus but because of a university stuff up we have to do it online...it was not a choice...it is offered online therefore you can do it online...I didn't want to do it and I found it unmanageable (sic)...no feedback...no practical help and knowing that whejn (sic) you go to lectures you do get MUCH more than the notes online....and in tutorials you are able to ask questions that 'fix' problems because you can gauge the correct answer viz the tutors's expression etc...days of no feedback on line caused me to drop the subject...groupwork that required online students to do 4 times the work as there are no groups in space...I was already doing 3 other units...4 times the work in one is unacceptable..." (Student \#7)

However the commentary was not all negative. Twenty-five students $(57 \%)$ were enrolled in units that contained orientation activities. While responses were generally positive, students wanted a generic orientation or virtual orientation to study at university. Some students also took the time to comment favorably on the online mode.

"Otherwise this has been a great learning experience and I will be forging ahead." (student \# 23)

"Otherwise, I think Ecourse is a very innovative service and I have always found it user-friendly in terms of access and maneuverability (sic)." (Student \#10)

"I find online study very convenient and better than on-campus. I like being able to access ecourse from anywhere, anytime. This means I can go on holidays with my kids during school holidays and still be able to do my course." (Student \#46)

The student commentary appears to support the data collected in the survey. Major issues for students are still contact with their lecturer, feelings of isolation and anxiety, lack of confidence and motivation.

\section{Conclusion for First Experiences of Online University Study}

FYE research has looked closely at on-campus student experiences in order to assess what factors make for a successful first year at university. This research has identified isolation and lack of identity as major impediments to success. While these factors are also evident in the emotional response of students in the survey group, lack of confidence,frustration and anxiety also appear to be key factors. The findings from this survey suggest that lack of confidence, feelings of isolation and anxiety are closely related. The findings from this study also suggest that the lecturer is a central figure in the online learning environment. The presence of a pro-active lecturer who gives prompt feedback, has and maintains early and consistent contact with students, appears to counter-balance the students need and preference for face-to-face instruction as identified in the literature. While a number of students were still experiencing technical difficulties, the frustrations and increased anxiety experienced by students and described in the literature (Hara and Kling, 1999) appear to be associated more with lack of confidence and feelings of isolation in this survey group. This result may be due to the fact that the eCourse system is extremely robust and students experienced very little down time during the semester. The age of students has also been identified in the literature (Oliver, 2003) as a factor for limited success at university. It has been suggested that mature age students entering university for the first time have poor technology skills. Age and technical readiness do not appear to be significant factors in this survey group which contains a high proportion of mature age students, many of whom have studied at university before.

Is the online environment a factor for successful student learning and integration into university life? Certainly, the findings in this study suggest that first experiences do create difficulties for some students and leave lasting impressions of feelings of isolation, lack of confidence and anxiety. What the data from this survey does tell us, is that the LIS students' emotional response to online study and their feelings of anxiety and confidence are closely related to feelings of isolation and their ability to connect with the university and the online/on campus community. One way of emulating the on campus experi- 
ence of belonging to a university culture and learning community, is the incorporation of (asynchronous) discussion forums into online units. The use of discussion forums is the focus of the second part of this paper.

\section{Using Discussion Forums to Create an Online Learning Community}

Encouraging students to participate in discussions is always challenging. It is even more so when the students are studying online and never meet face-to-face. All the social signals of body language that encourage conversation are absent: there is none of the welcoming smiles or eye contact that helps to break the ice in a classroom. Initiating and sustaining a conversation without these social aids takes courage and perseverance. Although that barrier is significant, two more must be added to the hurdles faced by online students. One is the expectation of working in isolation: that distance study will consist of reading provided or suggested resources and submitting essays as assignments; and the other is the challenge of acquiring, installing and managing the technology. The challenge of the technology is very significant and potentially affects all enrolling students. School leavers may consider they are proficient Internet users given their secondary school experience, but have never had to set up personal facilities for Internet access. Older students often acknowledge their lack of confidence during pre-enrolment conversations with course coordinators, asking about skill levels required and discussing the possible need to take a community-based computer skills course to ensure they will be able to cope. Students who have permission to use Internet access for professional education at their place of employment may encounter firewalls that prevent downloads. This problem requires them to enlist the help of both the University's and their organization's technical support in a frustrating and time-consuming quest for a way to work-around the barrier for access to their online study resources. Lecturers' experience in responding to requests for advice and assistance indicates few online students sail calmly through the beginning of their first semester's online studies. Thus anxiety is often reinforced by experience, resulting in the feeling that they are falling behind and don't have time to spend in discussions or chat on an online forum.

Experience in recent years in courses for the Information Science professions provided by the School of Computer and Information Science at ECU, has shown that if participation in forums is offered as an optional, unstructured and purely social means of overcoming their isolation, a few will take up the opportunity with enthusiasm, more may try if prompted by the tutor, but few sustained conversations and very little regular participation will result. It is clear that beginning online students need a powerful incentive to overcome their reluctance and participate constructively in online forums. Thus a strategy has been devised whereby discussion forums are used as a vehicle for structured assessment. Students are provided with three problems or issues that they must first research for themselves, write an initial contribution of approximately 500 words and post that to the forum for their group on a particular date. Then they are asked to participate in constructive discussions and feedback to other students, asking questions, endorsing opinions, adding information they have found. At the end of the semester, students are assessed on a collation of their initial postings for each problem together with what they consider to be their two best responses to other students for each problem.

The comments that follow are taken from those reflections provided by a group of students undertaking one of their final units, called Documenting the Corporate Memory, which covers issues in and standards for archival description and provision of public access to archival records. These comments are extracted, with permission, from a reflection required as part of their assessment on whether the process of using forums has enhanced their learning in the unit. It is interesting to note that at this stage, none mentions problems with managing the technology. It seems such problems have been overcome and are no longer an issue.

This strategy of assessment through discussion forums is used in four of seven units in the archives and records discipline area. Full time postgraduate students in these courses will be in their second semester when enrolled in the last unit that employs forums to facilitate online studies. Many students in these courses complete their studies part-time, and have worked online for four, six, or even more semesters by the time they reach their final semester. They are seasoned users of discussion forums by this stage and their comments are particularly interesting, for they offer insights as to whether working online becomes easier. Undergraduate part-time students are working through the equivalent of three years' full time study. 


\section{Student Endorsement for Online Discussion Strategies}

There is a strong consensus that the assignment forums provide a stimulating experience and broaden students' knowledge, drawing on shared research and experience. Anna, a postgraduate student, put it very well:

"The forum discussions allow me and other students to benefit from the knowledge of others. Through the discussions it became clear that some students have a good understanding and/or a background in information technology. It was useful to read their interpretations of the issue and gain a greater understanding of how P2P networks work. Forums served a useful purpose; they allowed students to share and further their knowledge and to see issues from new perspectives by expanding discussions into areas that the individual student may not have considered through their own study."

Judith, a seasoned undergraduate student, wrote:

"Research of these topics uncovers a wealth of information about the exploration taking place in national and international archival communities. The process of sharing the sources of such information leads to a greater understanding of the topics."

Donna reflected:

"The topics that were covered in these problems were often quite complex, and it was difficult to fully grasp some of the concepts that were presented in the associated readings....

However, as in the past, these online forum discussions have been an extremely helpful means to condense and absorb the concepts. The level of analysis of the topics that is required to write an initial posting assisted in providing a fairly in-depth understanding of the problems. Reading and discussing other points-of-view on the topics helped to form even stronger opinions and ideas on the issues. ...

Unfortunately, the amount of time required to write responses didn't allow me to participate in discussions as much as I intended to. However, overall, I think that the process of reading other students' opinions and interpretations enabled me to gain a broader understanding of the issues, particularly the posts from those who were able to relate real-life experiences from working in a records-related field."

Lee, also an undergraduate student explored these views in more depth:

"Knowing that my peers will make constructive comments gives further impetus to producing the best work I can in the time frame available. I do not feel able to give any opinion on a problem unless I have grasped the concepts in depth.

It is very interesting to see the breadth of sources used by other students and the differing conclusions reached. The same basic information can be viewed from a number of different angles. It is enlightening and thought provoking to consider others' insights, which may be complementary or opposing to my own.

Whilst I find the research stimulating, the challenge lies in considering other interpretations and responding constructively. At times I have been impressed with the lucid grasp another seems to have of the subject with which I have struggled. Alternatively, I may find another's impressions to be so at odds with my own that I feel compelled to persuade that person to the contrary point of view, based on evidence I have found. ....

The interaction with fellow students has built camaraderie and enabled us to find support within the group. Over time, I have warmed to the idea of the discussion group and now view it as a vital learning curve in my quest for knowledge and understanding of the subject."

Loretta believes her participation in the forum discussions has contributed to successes in the workplace:

"Overall, I firmly believe these exercises have contributed directly to my confidence in the 'professional discussion' arena in the workplace. For example, I recently successfully negotiated the inclusion of a separate (business unit) records unit to come under the reporting structure of my records unit. These negotiations took place with two senior Executives and involved my presenting a list of pros and cons followed by a credible and convincing argument where I could see was making a positive impression as I spoke. I could not have achieved this a couple of years ago and attribute these skills directly to the forum postings and the course overall."

\section{Continuing Anxiety in Online Students}

All of the above add up to a strong endorsement for requiring participation in online discussions to overcome feelings of isolation and increase student satisfaction with online studies. However, let us return to our concern with student anxiety. Although there is consensus among the students that the forum discussions have been beneficial, two in a group of nineteen students, all with significant experi- 
ence of online study and forum discussions, indicated this style of assessment is still accompanied by significant anxiety or reluctance to participate. Linda, a part-time undergraduate student, reports:

"I enjoyed reading all the other postings and I did learn more and more from the others. But for my answers I felt that they were not very good at all. As I struggled with the understanding and then struggled with answering other peoples comments.

Over all I did learn more than I would have just from reading the readings, I learnt from the other postings and the research they did as I found some different sites that I had not found. But overall I did struggle with the whole concept of being out in front of the other students. ... I found that when the other students answer with so much depth it makes me feel very inadequate."

Linda suggested progressive feedback from the tutor on postings before the assignment is complete would help to allay these fears. No doubt she is right, because Linda's work on the forums displayed a sound methodical approach to topics she knew little about at first and some reassurance may well have helped build her confidence. In her postings to the second problem, she worked logically through the definitions and issues and in so doing helped make the topic clearer for herself and for others. In problem 3, her approach paid off again, conveying to fellow students in straightforward terms what P2P networks are and what the inherent problems might be as well as the advantages. In other words, she needed confidence building, rather than assistance with her approach to the set problems. But Anderson et al. (2005) note:

"On Forums set up for discussing specific problems, the tutor should not intervene unless inaccurate or misleading information is posted. Students are encouraged to manage their own discussions, to encourage each other and to maintain a professional standard. Intervention by the tutor runs the risk of being seen as the 'right' answer which might then stifle the discussion."

There is a real danger that intervention by the tutor will interrupt the flow of conversation. More importantly, it runs the risk of reducing students' ownership of the conversation and their understanding that it is their responsibility to support and encourage each other by maintaining the flow and to constructively evaluate and build upon others' contributions. If it were done at all, it would need to be private, formative feedback provided to each individual and not in the form of tutor's comments readable by all on the forum.

And finally, Louise's reflection reveals a depth of self-awareness and concern that led her to search the literature on online learning for endorsement of her own communication strategies:

"A recent study examining online learning in universities concluded that "only bulletin board use influenced achievement, with those posting messages outperforming those not using, or passively using bulletin boards".(Hoskins, 2005) Unfortunately I continued my love/hate relationship with Bulletin Boards and was again too passive in my use to gain the full benefit. I am getting better. I am extremely grateful for the opportunity to order my thoughts and put them out into the arena. This opportunity benefits my personal learning enormously. However, the lack of face-to-face or even a real time chat session (as with other subjects) makes for some pretty uneven "discussion" and therefore learning. I am still caught in a web of my own making. I am afraid I find it frustrating not to be able to chat and I am not brimming with confidence so I don't readily initiate "conversation", especially in a constricted communication environment! I found a slight work around to this problem for myself, by responding directly to particular student colleagues whenever they responded to my postings. Unfortunately one of my postings did not even get a response and in that situation I just had to comment on other postings! Is what I wrote rubbish? Did I drop "pearls of wisdom" into the discussion? Unfortunately I will only know when I get my results and that is too late. I will admit to a little devious behaviour to force some discussion on my postings so that I could start chatting - I left my references off my original postings to Problems 2 and 3. As you can see, I got some respondents!

An earlier empirical study undertaken by Karin Schweizer in 2003, found that "learners in the blended learning condition who worked together face-to-face led a much more coherent discourse than learners in the pure e-learning conditions." The 2003 study supports my student experience and communication methods I use in the workplace. I always attempt to mix electronic communication with face-to-face and/or other voice communication and avoid situations where this is not possible. For instance I will utilise e-mail as an opening form of communication for a face-to-face or telephone meeting or speak to a paper that I have written before it is handed out. I may be shot down in flames or not, but at least I have maximised my chances to communicate my message and learn from others."

It is particularly interesting that Louise, in the process of reflecting on her "love/hate relationship" with discussion forums explored the literature on elearning, perhaps in an attempt to understand her own reactions. She has demonstrated that she is self-motivated and she is comfortable using the technology. Yet, despite her maturity, experience in studying online at a distance, her commitment to her studies and her competence in seeking and retrieving information, Louise has found the lack of face-to- 
face communication very trying. Her anxiety is exacerbated when other students don't respond to her posting.

\section{Conclusion for Using Discussion Forums to Create an Online Learning Community}

The students in the second study were all proficient users of technology and had extensive prior experience studying in the online environment. While it is clear from these responses that the discussion forums have built a community of learners, the online experience and mode of delivery is still a significant factor in student satisfaction with university study. Even these veteran online students experienced frustration, anxiety and lack of confidence. These two studies indicate that lecturers and universities need to provide additional support for online students. For online learning to be a satisfying and successful experience for students, information about courses and expectations need to be transparent, the technology easy to use and accessible, two-way communication between the lecturer and the student consistent, and the development of peer-to-peer discussions encouraged. Only when these additional support structures are provided, will isolation, lack of identity and confidence, anxiety and a lack of motivation to study cease to be major impediments to success when studying online at university.

\section{References}

Anderson, K., Clayden, J., Combes, B., Ring, J. and Williams, T. (2005). Out of the frying pan and into the spa: Developing an online learning community and culture, Pacific Asian Education: A Journal about Education in Pacific Circle Countries, 17(1), 44-53.

Doubler, S, Harlen, W, Paget, K and Asbell-Clarke, J. (2003). When learners learn on-line, what does the facilitator do? Paper presented at the British Educational Research Association Annual Conference Edinburgh, September 11 - 13, 2003 [Online]. Retrieved on 4 May 2004 from http://brs.leeds.ac.uk/ beiwww/beid.html

Duderstadt, J.J., Wulf, W.M. and Zemsky, R. (2005). Envisioning a transformed university: Change is coming, and the biggest mistake could be underestimating how extensive it will be. Issues in Science and Technology, 22 (1) $35-43$.

Hara, N and Kling, R. (1999). Students frustration with web-based distance education course. First Monday, 4(12) [Online]. Retrieved on 13 June 2004 from firstmonday.org/issues/issue4_12/hara/index.html

Hoskins, S. (2005). Motivation and ability: Which students use online learning and what influence does it have on their ability? British Journal of Educational Technology, 36(2) 177.

Latham, P. and Green, G. (1997). The journey to university: A study of 'the first year experience, Royal Melbourne Institute of Technology [Online]. Retrieved on 4 May 2004 from http://ultibase.rmit.edu.au/Articles/dec97/greenlath1.htm

McInnes, C., James, R. and Hartley, R. (2000). Trends in the first year experience in Australian universities. Centre for the Study of Higher Education, University of Melbourne [Online]. Retrieved on 30 January 2006 from http://www.dest.gov.au/archive/highered/eippubs/eip00_6/fye.pdf

McInnes, C., James, R. and McNaught, C. (1995). First year on campus: Diversity in the initial experiences of Australian undergraduates. Centre for the Study of Higher Education, University of Melbourne [Online]. Retrieved on 30 January 2006 from http://www.autc.gov.au/pubs/caut/fye.pdf

Oliver, B. (2003). Transition to university: What the research says [Online]. Retrieved on 4 May 2004 from http://lsn.curtin.edu.au/learning_matters/03february/transit.html

Oliver, R. \& Omari. A. (2001). Exploring student responses to collaborating and learning in a Web-based environment. Journal of Computer Assisted Learning, 17(1), 34-47.

Oppenheimer, Todd. (1997). The computer delusion, The Atlantic Online, 280 (1).

Salmon, Gilly. (2002). Etivities: The key to active online learning, London: Kogan Page.

Sander, P., Stevenson, K., King, M. \& Coats, D. (2000). University students' expectations of teaching. Studies of Higher Education, 25(3).

Schweizer, Karin. (2003). Blended learning as a strategy to improve collaborative task performance. Journal of Educational Media, 28(2/3) 211.

$\mathrm{Tu}, \mathrm{H}$. and Corry, M. (2001). A paradigm shift for online community research. Distance Education, 22(2).

Werry, C. (2002). The rhetoric of commercial online education. Radical Teacher, Spring (63).

Zemsky, R., \& Massy, W. (2004). Thwarted innovation: What happened to el-learning and why [Online]. Retrieved 19 July 2005 from http://www.thelearningalliance.info/Docs/Jun2004/ThwartedInnovation.pdf 